\title{
Infrastructural Interactions Governance Model of Urban Services in the Context of Socio-Economic Development of the City
}

\author{
Evgeniya V. Ufimceva \\ Nikolai N. Minaev \\ Irina V. Volchkova \\ Yuliya A. Merkuleva \\ Tomsk State University of Architecture and Building, Russian Federation \\ Email: Ufimtseva80@mail.ru
}

\section{Doi:10.5901/mjss.2015.v6n3s5p183}

\begin{abstract}
In the present article reveals the developed and validated methodical approach to the management of infrastructural interaction of municipal services in the context of socio-economic development of the city, which is based on the balanced scorecard. The process of determining the functional interactions of the leading infrastructure of the city with other infrastructures of municipal services is systematized. A basic model of infrastructure interaction management of municipal services in the context of socioeconomic development of the city is elaborated.
\end{abstract}

Keywords: infrastructure, municipal services, social and economic development, balanced scorecard

\section{Introduction}

The formulation of socio-economic development program of the city is one of the underdeveloped sections in the practice of municipal governance. Obviously, the elaboration of socio-economic development program of the city is for decades being fundamental to effective implementation of the city functions. Notably, the effective organization of the city and its compliance with its functions depends on the state and development of infrastructure. In this regard, infrastructure forms the image of the city and its image in the settlements of the townspeople. It is important to pay attention to the widespread development of infrastructure, otherwise in a period of time the city will not be able to perform its functions (Ratajczak, 1999). Infrastructure is generally understood as agencies and institutions that are necessary for the effective functioning of the economy and the livelihoods of people in the area (Dziembowski, 1966, 1985; Ginsbert-Gebert, 1972).

Currently, the law requires transparency, clarity and accountability, timeliness, and easy access to a wealth of socio-economic data area from the the management process of socio-economic development of the city. The main objective of long-term socio-economic planning of the city is the coherence of the economic and social policy with the objectives to create long-term sustainable socio-economic development and improve the level and quality of life. The special role of the city in this process is defined by the fact that it is able to more fully take into account the particular socio-economic and cultural development of the local community, flexibly responding to local needs.

An increased responsibility and greater independence of the subjects of the budget process and administrators of the budget funds, as well as the clear medium-term (three-year) targets established are the positive ongoing reform of municipal finance. As a result, it is possible to adopt and implement a number of medium term targeted programs within the framework of socio-economic development of municipal regions (i.e. urban districts). Therefore, control and evaluation of urban infrastructure that meets the needs of the urban population is an urgent problem (Yeliseyev et al., 2009). All been said, it is important to note that when researchers are turning to the problems of city's infrastructure, they concentrate on research of infrastructure of individual industries' complexes of urban economy. The scientific problem here is as follows:

1. lack of description of the infrastructure of municipal services and the linkages inbetween this socio-economic subsystem of the city;

2. there is no methodological framework for assessing the balanced development of urban infrastructure, since the evaluation should has a compex nature. 
Thus, the vagueness pf the two notions mentioned above have a negative impact on the pace of development of urban infrastructure and does not enable to optimize their activities in a complex nature. The purpose of this study is to develop a theoretical and methodological approach to the governance of interactions of the municipal services infrastructure in the context of socio-economic development of the city which is based on the balanced scorecard.

\section{Methodological Basis of the Study}

A number of scholars worldwide have devoted their research to the assessment of the effectiveness of infrastructure, among them are the works of N.V. Novikov, P.E. Animitsa, M.S. Weeds, W. Izard, L.N. Linkeytseva, D. Webster, L. Muller, A. Ginsbert-Gebert, and others. While many issues regarding the governance of urban infrastructure development under the current global socio-economic processes that have led to the emergence of new patterns and trends in the development of urban infrastructure governance research. Lack of full understanding of this issue affects the practical aspects of the designated problem (Ufimtseva, 2014).

To date, the economic literature most fully represents the criteria and methodology for assessing the effectiveness of the development of enterprises, regions and countries. The evaluation mechanism of an integrated infrastructure development of the city is least developed. As the level of infrastructure development and the effectiveness of its functioning have a significant impact on the state of the economy, which ultimately determines the quality of citizens' life, the main approaches to its assessment should be considered.

Animitsa and collagues (2009) propose typological comparison of regions. The comparison typology of regions is understood as the separation of different regions of the country into several homogeneous groups. These groups are being allocated on the basis of one or more most important criteria, attributes, relationships and organizational levels of both quantitative and qualitative data in order to identify, compare, and provide an ordered description (Animitsa et al., 2009).

Buryanov and Maksimov (2008) offer a simple scheme of comparative evaluation of the efficiency of the regional infrastructure complex functioning using the the potential analyzing method, being tested in an example of the municipality. The technique involves methods of complex and piecemeal (i.e. individual elements) evaluation. An integrated (i.e. complex) assessment is carried out for inter-municipal comparison and understanding of a particular situation of the region and urban districts on the general background. As part of this task, it is proposed to carry out the ranking method of the main indicators of socio-economic development: a) calculation of the average rating values of the main indicators of a complex infrastructure development of the region (i.e. the dynamics of population, household income, level of development of transport, the share of consumer expenditures, etc.) and the final rating for the entire list of indicators; b) ranging of rankings. Thus, this method justifies the grouping of the mentioned procedures in terms of infrastructure capacity of the territory or by the favourability of life quality. Systematic analysis over the years allows us to follow trends in changes of infrastructure capacity of the territory as a whole, as well as its components. The item-score is used in a detailed study of a particular municipality. It operates over a wide range of indicators and is held for an indepth research, affecting all levels of study: the region as a whole, the villages and settlements. Important procedure of the piecemeal evaluation is the selection of indicators.

While selecting a list of indicators it is important to consider the credibility and availability of indicators, as well as the ability to reflect the specific features of the object of analysis it its fullness and adequatecy (Burian and Maksimov, 2008).

From our point of view, the positive aspect is that this method is simple enough to use, as available statistics is being used in the evaluation process. However, the results will enable an objective assessment of the comparative analysis of the municipality and the region as a whole. Since the development of each region is defined by the specificity of its geographic location, industry specialization and localization, a simple comparative assessment of infrastructural components of the region will not enable regions to develop an adequate mechanism for the formation and development of the infrastructure complex a particular city.

The most famous of the analysis was proposed by W. Izard. The purpose of this analysis is not as much to identify sectors that can make the most of the rich resources of the area, but in determining which of them will lead to the diversification of the economic base. This analysis is necessary to identify possible areas of regional development, which were previously dominated by secondary industries or small businesses, or both simultaneously. The objective of the analysis is to examine trends in the development directions of one or more industries based on raw materials or markets. In order to obtain quantitative information, W. Izard (1966) proposes to use the coefficients of localization. They provide the basis for pre-selection and promotion of various sectors in the region. Low coefficients indicate a relatively low concentration of the industry in geographical terms, and hence that it is suitable for placement in areas seeking to 
diversify. The main feature of the coefficients of localization - the possibility of comparing the percentage of distribution of the two parameters in the area-section (Izard, 1966).

In order to assess the socio-economic development of the region, Lineytseva (2006) suggests using a method based on an integrated (multi-factor) evaluation. An integrated assessment of the level of socio-economic development of regions begins with the formation of the system of partial indicators that should meet the following requirements:

- characterize various aspects of socio-economic development of the region;

- not be dependent on each other (i.e. the correlation coefficients between each pair of indicators should be minimal);

- indicators should be the relative values.

Next, we calculate the normalized values of these parameters for each region. Coefficients of factor's significance of particular indicators of socio-economic development of the region are first being transformed into a rank. Then, the amount of the transformed ranks is calculated. After the conculation been made, the regions are ranked by descending integral coefficient by the level of socio-economic development, either ascending depending on the formula selected for the calculation (Lineytseva, 2006). This technique is most applicable for the assessment of infrastructural complex of the region, but not the city.

The methodology developed by the authors under the supervision of J. Kalyuzhnova is being based on the Competitiveness Index, determined by two main parameters - general competitiveness parameter and the competitive advantage parameter. The general competitiveness index is based on the elimination of the arithmetic mean of 12 partial indices, calculated on the basis of particular indicators. Among individual indicators chosen are: the volume of GDP per capita, share of exports in gross regional product, GRP growth rates, labor productivity, wage capacity, the return on fixed assets, the density of paved roads, the investment per capita, share of employment in research and in the field of information, the number of small businesses per 10 thous.pers., financial security per capita (Kalyuzhnova, 2003). In our opinion, the list of indicators is ambiguous, as for the evaluation of infrastructure advantages the railways, airports are no less important that using only the density of roads. The standard of living is estimated by using the gross regional product per capita, but not the level of development of education and health in the region, housing provision and others is taken into account.

Grincell and Kostyleva (2003) encourage using ranking method and the method measuring the potential of the territory. The first one iplies using the rank score for a group of characterizing geographic location and socio-economic development of regions (23 indicators), which allows us to estimate the overall socio-economic situation of the region in the space of the country. In this procedure, there are three groups of parameters subdivided: the socio-economic assessment of the competitiveness level, the level of specialization of the region, the evaluation of the profile of the region's share of production of certain types of industrial products in total Russian production. The second approach is based on the measurement of territorial capacity: resource, financial, environmental and institutional. From our point of view the downside is that the assessment of the potential is represented abstractly without specific description of the calculation of these parameters.

International Institute for Management Development proposes to use four groups of factors: the economic situation, the effectiveness of state regulation, the performance of the business and infrastructure. In each of the four groups, a large number of indicators are being used. For example, as to assess the economic situation a total number of 77 criteria being used, to assess the infrastructure - 95 criteria.

International organizations estimate the degree of regional development using integrated indicators. These indicators can be taken to assess the level of development of social infrastructure in the region, as being meaningfully linked. One such indicator is the Human Development Index, developed in the framework of the "Development Programme" of the UN. It ranks countries on the scale from zero to one. Three indicators of economic development are being used for the calculations: life expectancy at birth, intellectual potential (i.e. adult literacy and mean years of schooling), the value of the per capita income in purchasing power of the currency and reduce the marginal utility of income (SSRN, 2000; 2005; 2008).

In determining the integral index in the evaluation on the basis of statistical indicators, each author offers own set of indicators (Haughton \& Sirin, 2004; Parkinson, 2003; Webster \& Muller, 2000). The techniques differ in the amount and composition of the investigated groups of indicators. At the same time there are common elements, as a rule, methods include evaluation of different types of potential of the territory, the investment attractiveness, efficient use of the resource base, the standard of living of the population.

Authors such as Burak (2009) and Zotov et al. (2008) rightly argue in their designs, that the methods of regulation of social and economic relations in large cities should be based on a combination of scientific research, considering the urban economy as a complex socio-economic system. Such regulation must be based on "soft" change of the relationship 
between the structural elements of the system by agreeing on liability based on the fact that the interests and responsibilities of interacting systems of municipal market must be balanced.

Zotov and colleagues (2008) notes that with regard to the specifics of housing and communal services market can be considered as a sphere of demand and supply formation of products and services to businesses and organizations of utility services. Given that supply and demand in the field of such services and products cannot be found in other markets, the market for municipal services has such properties as monopoly and independence. Needs of the population, as well as companies and organizations in the utility services determine the utilities supply and demand. At the same time, this market is closely related to repair and construction business, labor market, and construction materials markets. There is also a direct reference to the investment market. In our view, this approach is best suited to evaluate the effectiveness of the city's infrastructure and management decisions, but not adequately covered in the scientific literature, especially in relation to the assessment of infrastructural interaction of the city.

Thus, a review of the main approaches to the study and evaluation of infrastructural complex of the territory has determined that the proposed approach and toolkit enable to evaluate and explore the trends of infrastructural development at the macro level, i.e. the economic development of the region or country. This in turn does not reflect the infrastructural components and the socio-economic development of the city. In this regard, is urgent to develop a methodical approach to the governance of infrastructural interactions of municipal services in the context of socioeconomic development of the city.

\section{Methodical Approach to the Effective Development of Urban Infrastructure}

Figure 1 graphically represents a methodical approach to the governance of infrastructural interactions of municipal services in the context of socio-economic development of the city, which is based on the Balanced Scorecard (BSC). The BSC includes four components: customer, financial, internal processes and learning (i.e. development, innovation), taking into account both financial and non-financial indicators (see Kaplan and Norton, 1996).

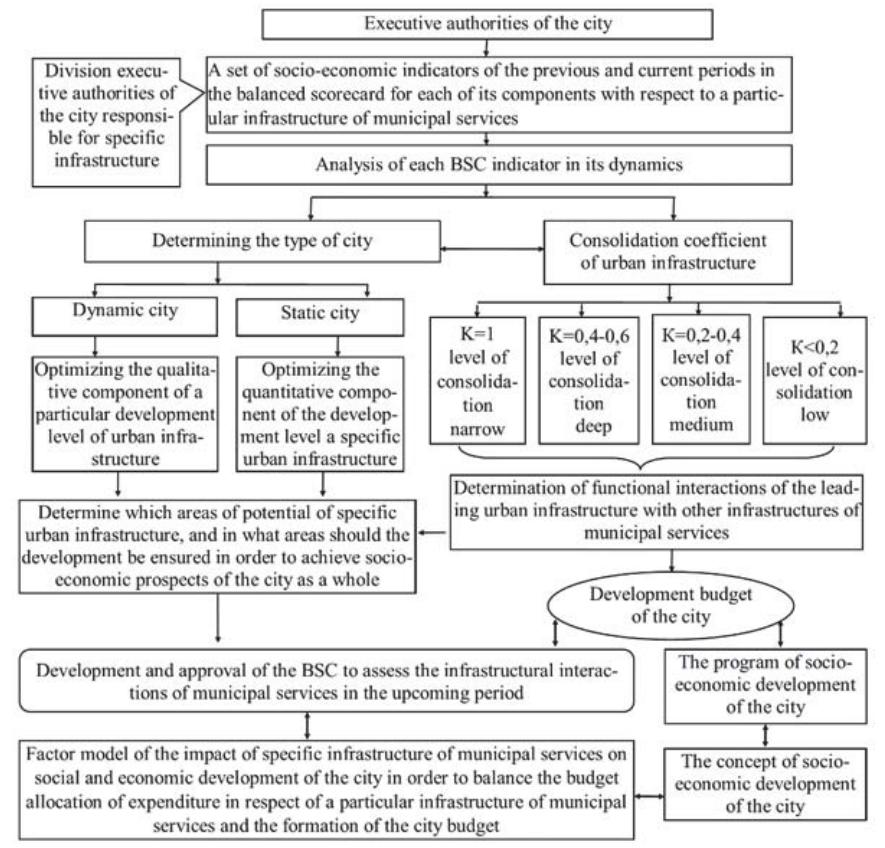

Figure 1. Methodical approach to governance of infrastructural interactions of municipal services in the context of socioeconomic development of the city based on the balanced scorecard

The proposed methodical basis build upon the balanced scorecard allows to present data from disparate infrastructural sources into a single structure of calculations, which will provide the necessary transparency of the city's infrastructure 
development for decision-making process by the executive authorities of the city. We shall justify the major points of the methodological approach to the governance of infrastructural interactions of the municipal services in the context of socio-economic development of the city based on the BSC.

Step one. Consolidate a set of socio-economic indicators of the previous and current periods in the balanced scorecard for each of its components with respect to a specific infrastructure of municipal services by the departments of the executive authorities of the city, responsible for specific infrastructure. It is required for the formation of a single calculation base.

Step two. The analysis of each indicator of the BSC in its dynamics. This is required for a clear understanding of the current state of development of the infrastructure of the city in relation to the previous periods.

Step three. Calculation of the consolidation of the urban infrastructure in order to determine the leading infrastructure of the city. The consolidation coefficient of urban infrastructure is determined by the following formula

$$
K_{\mathrm{CC}}=\frac{100}{y_{\mathrm{C}}(2 i-1)},
$$

with $K_{\mathrm{CC}}$ - consolidation coefficient of urban infrastructure, $y_{\mathrm{C}}$ - the share of infrastructure in total economic turnover of the city, ${ }^{i}$ - the serial number of economic turnover of the relevant urban infrastructure in the rank.

Step four. Determination of functional interactions of the leading urban infrastructure with the rest of municipal services infrastructure. This is necessary because the largest share of urban infrastructure is fairly broad and universally significant, respectively. The functional interaction of the leading urban infrastructure with the rest of the city's infrastructure refers to the implementation of functions by the governance subjects of the leading infrastructure that, in turn, affects the creation of the necessary framework conditions for the normal functioning of all other economic agents of the city and establish relationships between governance subjects in the sphere of municipal services.

Step five. Determining the type of city. We propose to use two basic concepts, the "dynamic city" and the "static city". The concept of "dynamic city" refers to the level of development of the city, characterized in relation to the previous period of active growth in production, population, decrease in unemployment and stable ecological situation. The concept of "static city" refers to the level of development of the city, characterized with respect to prior periods of fixed or reduced production, population, increased unemployment and tight ecological situation. The main criteria for classifying the city to a certain type is to evaluate a range of indicators over the 10-20 years period. Such as: the level of production volumes; the rate of unemployment; the population of the city; the state of the environmental situation; the level of business development; the volume of investments in fixed assets. The "static cities" are the cities that over the last 10-20 years' period demonstrate a reduction of $10 \%$ or more, as well as showing the growth dynamics within the city as unchanged or negative.

After classifying the city to the appropriate type, decision is being made towards its development path. In dynamic city defined by the active internal social and economic development processes, it is proposed to optimize the qualitative component of the level of development of a particular infrastructure. In a static city, chatacterized by the inactivity of domestic social and economic development processes, it is proposed to optimize the quantitative component of the level of development of a particular infrastructure.

Step six. Combining the results of the steps 3-5, and identifying the potential areas of specific infrastructure of the city, and the optimal development path to achieve socio-economic prospects of the city as a whole.

Step seven. Development and approval of BSC to assess the infrastructural interactions of municipal services in the upcoming period.

Step eight. Building the factor model of the impact of specific infrastructure of municipal services on social and economic development of the city in order to balance the budget allocation of expenditure in respect of a particular urban services' infrastructure and the formation of the profitable part the city budget. This factor model is based on the economic dependence of the turnover of specific municipal services infrastructure and the revenue side of the city budget with the construction of the equation of the trend and outlook for 3-5 years.

Step nine. The results of all the eight steps are to be considered when developing the concept of socio-economic development of the city, being the basis of the socio-economic development program.

Step ten. Implementation of the program of socio-economic development of the city, which includes the drafting, review and approval of the budget of the city. Approval of the city budget has be done while considering the steps 7-8 of this methodological approach.

Figure 2 graphically depicts the basic governance model of infrastructural interactions of municipal services in the context of socio-economic development of the city. 


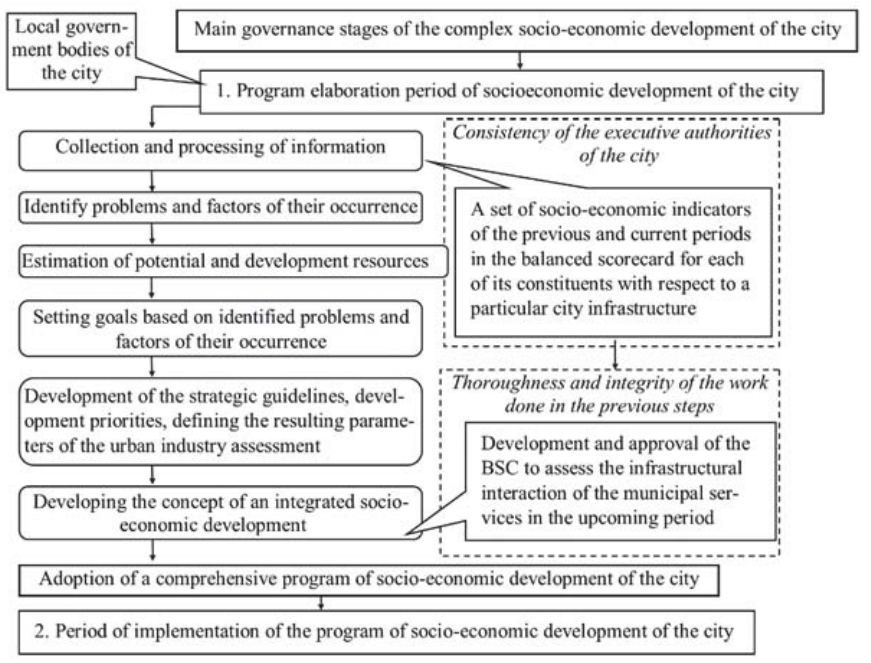

Figure 2. Basic governance model of infrastructural interactions of municipal services in the context of socio-economic development of the city

\section{Conclusion}

The present study proposes a solution to the problems outlined above by the use of the author's governance model infrastructural interactions of municipal services in the context of socio-economic development of the city, focused on changing the conditions arising in its infrastructural sphere.

Summarizing the main provisions of the study, the following conclusions are to be made. Using the developed methodical approach to the governance of infrastructural interactions of the municipal services enabled to explore the complex dynamic objects (i.e. infrastructure of the city); consider possible development path of a particular infrastructure of the city; develop a balanced budget for the urban development while considering the indicated factor model. The proposed governance model of infrastructural interactions of the municipal services is able to solve the problem of ensuring the transparency of complex infrastructure of the city, icrease the expenditure efficiency, improve the organization of the infrastructural complex of the city in the context of harmonization of work and improve the quality of socio-economic development.

\section{References}

Animitsa, P. E., Novikova, N. V., \& Khodus, V. V. (2009). Typology as a method of studying the socio-economic development of the region. Proceedings of the Ural state University of Economics, 23(1), 52-59.

Burak, P. I. \& Roslyak, Y.V. (2009). Fundamentals of the big city economy. Moscow: Economics.

Burian, M. S., \& Maksimov, A. A. (2008). Experience in assessing social capacity of municipalities. Economic and social changes: facts, trends, forecast, 2, 96-106.

Dziembowski, Z. (1966). Pojecie infrastruktury i jej charakterystyka. Miasto, 2.

Dziembowski, Z. (1985). Infrastruktura jako kategoria ekonomiczna. Ekonomista, 4-5, 725-739.

Ginsbert-Gebert, A. (1972). Infrastruktura i jej rola w rozwoju miast. Gdansk.

Grincell, B. M., \& Kostyleva, N. E. (2003). The most important factors for increasing the competitiveness of regions. St. Petersburg. [Online] Available: http://www. regionforum.ru/forum/materials (February 04, 2015).

Haughton, J., \& Sirin, C. (2004). BHI Metro Area and State Competitiveness Report. Boston, MA: Beacon Hill Institute at Suffolk University.

Izard, W. (1966). Methods of regional analysis: an introduction to the science of regions. Moscow: Progress.

Kalyuzhnova, N.Ya. (2003). Competitiveness of Russian regions in the context of globalization. Moscow: TEIS.

Kaplan, R. S., \& Norton, D. P. (1996). Using the Balanced Scorecard as a Strategic Management System. Harvard Business Review, January-February, $75-85$.

Lineytseva, L. N. (2006). Integral assessment of the level of socio-economic development of the region. Vestnik of Tomsk state University, 7, 42-44. 
Parkinson, M., Hutchins, M., Simmie, J., Clark, G., \& Verdonk, H. (2003). Competitive European Cities: Where do the Core Cities Stand? A report to the Office of the Deputy Prime Minister. London. [Online] Available: http://www.vrm.ca/documents/competitive.pdf (February 04, 2015).

Ratajczak, M. (1999). Infrastruktura w gospodarce rynkowej. Poznan: Wydawnictwo Akademii Ekonomicznej w Poznaniu.

SSRN (2000). The Social Rate of Return on Infrastructure Investments. [Online] Available: http://papers.ssrn.com/sol3/papers.cfm? abstract id=630763 (February 04, 2015).

SSRN (2005). The Social Return to Infrastructure Investments Using Interregional Price Gaps: A Natural Experiment. [Online] Available: http://papers.ssrn.com/sol3/papers.cfm?abstract_id=871167 (February 04, 2015).

SSRN (2008). Social Infrastructure: A Key Factor In Harnessing Demographic Dividend. [Online] Available: http://papers.ssrn.com/sol3/ papers .cfm?abstract_id=1079612 (January 31, 2008).

Ufimtseva, E. V. (2014). The study of urban infrastructure facilities in terms of regional socio-economic processes. Economic Revival of Russia, 2, 85-92.

Webster, D., \& Muller, L. (2000). Urban competitiveness assessment in developing country urban region: the road forward. Washington D.C.: INFUD.

Yeliseyev, A. M., Volchkova, I. V., \& Podoprigora, Yu.V. (2009). Problems of interindustry interactions in the context of economic development of territories (on the example of the Siberian Federal federal District). Scientific and technical sheets of the St. Petersburg state polytechnical university. Economic sciences. St. Petersburg State Polytechnical University Journal. Economics, 6-2 (90), 40-44.

Zotov, V. B, Baboon, R.V., \& Kirillova, A. N. (2008). The system of municipal management. St. Petersburg: Peter Press. 
